\title{
The Acquisition of English Intonation by Native Greek Speakers
}

\author{
Evia Kainada and Angelos Lengeris \\ Technological Educational Institute of Patras, Aristotle University of Thessaloniki \\ ekainada@teipat.gr, lengeris@enl.auth.gr
}

\begin{abstract}
This study examined the production of English intonation by Greek secondlanguage (L2) learners of English, specifically their production of polar questions and their pitch range in English. Productions of (a) comparable materials in Greek spoken by the same Greek speakers and (b) English materials spoken by native English speakers were used to assess phonological and phonetic native language (L1) transfer when learning an L2. The results showed that Greek speakers used their L1 (Greek) intonation in English polar questions. Greek speakers' pitch span in English was narrower from both their L1 (Greek) and from the target (English) pitch span.
\end{abstract}

\section{Introduction}

The acquisition of $L 2$ prosody, particularly intonation, is a very difficult task and the underlying processes involved in the acquisition of the intonational component of the L2 grammar still remain elusive for researchers and teachers alike. Despite findings showing that deviations in the production of L2 prosody (e.g. stress, rhythm, intonation) may affect listeners' judgments more than deviations in the production of L2 segmentals (vowels and consonants) (e.g. Derwing et al. 1998; Hahn 2004; Jilka 2000; Kang 2010; Kang et al. 2010; Munro 1995; Munro \& Derwing 1999, 2001; Pickering 2001), relatively little research has been done in the acquisition of L2 prosody. For example, apart from impressionistic data and intuitive predictions, no experimental study has examined the learning of English intonation by Greek speakers. The current study is a first step towards filling this gap as it applies a phonologically-motivated qualitative method to analyse the production of English polar questions by Greek speakers and their range of pitch when speaking English.

Research at the segmental level has shown that native language affects the learning of L2 vowels (e.g. Cebrian 2006; Flege et al. 1999; Flege \& MacKay 2004;

\section{(cc) BY-NC-ND}


Iverson \& Evans 2007; Lengeris 2009; Polka 1995) and consonants (e.g. Best et al. 2001; Guion et al. 2000; Hattori \& Iverson 2009; Iverson et al. 2003; Mackay et al. 2001). For example, Greek learners of English have difficulty perceiving and producing the English tense-lax /i:/-/I/ distinction (e.g. feel vs. fill) because they have a single vowel category /i/ in their vowel system (Lengeris 2009; Lengeris \& Hazan 2010). Likewise, Japanese speakers are very poor at perceiving and producing the English / $/$ /-/l/ distinction (e.g. rock vs. lock) because they focus on second formant frequency (F2) which is important for the perception of the Japanese voiced tap / $/$ / but is irrelevant for the English / $\mathrm{r} /$-/l/ distinction (Hattori \& Iverson 2009; Iverson et al. 2003).

Strong evidence that L1 transfer plays an important role in the way learners perceive and produce the $\mathrm{L} 2$ intonational patterns is also provided in the literature, but until relatively recently research focused on the errors produced by learners (e.g. Backman 1979; Willems 1982). More recent research (e.g. Mennen 2006) stresses the need to adopt a generally-agreed upon framework for intonational analysis to better examine cross-linguistic similarities and differences in intonation and, ultimately, to extend our segmental-level understanding of second language acquisition to the acquisition of L2 prosody. To this end, this study follows the autosegmental-metrical (AM) theory of intonational phonology (Pierrehumbert 1980; Ladd 2008), which has been applied successfully in recent $L 2$ intonation research (e.g. Atterer \& Ladd 2004; Jilka 2000; Jun \& Oh 2000; Mennen 2004, 2006). The AM theory distinguishes between the underlying phonological representation of intonation (e.g. tonal inventory) and its phonetic manifestation (e.g. Fo peak alignment) which allows for direct extension of speech learning models originally developed for the learning of $L 2$ segmentals to the learning of L2 intonation (e.g. Flege's Speech Learning Model, see Flege 1995).

Mennen (2004) adopted the AM theory to examine the production of Greek pre-nuclear rises in declaratives by experienced Dutch learners of Greek. At a phonological level, Greek and Dutch use identical pre-nuclear rises in declaratives, but the two languages differ in terms of the phonetic manifestation of the rise. In Greek, the alignment of the peak is realized in the vowel following the accented syllable whereas in Dutch the peak is realized slightly earlier, within the accented syllable. Mennen (2004) found that four out of five Dutch learners of Greek tested in her study transferred their L1 (Dutch) phonetic realization of the pre-nuclear rise in Greek (i.e., they aligned the peak earlier than Greek speakers) and only one Dutch learner showed native-like performance (i.e., her peak alignment values were within the norms for native Greek speakers recorded for control reasons). The present study focuses on one phonological and one phonetic aspect of the acquisition of L2 intonation, namely the production of English tonal targets by native Greek speakers in polar questions and the range of pitch they use when speaking English. This is an interesting $\mathrm{L} 1 / \mathrm{L} 2$ pair because, as will be discussed in the 
following section, there are major differences between Greek and English in the choice of tonal targets in polar questions (which are of course accompanied by phonetic differences in their implementation).

\subsection{Polar Questions}

Within the AM framework, Greek has received significant attention over the last years (e.g. Arvaniti \& Baltazani 2005; Arvaniti 2007; Baltazani \& Jun 1999; Kainada 2010; Tserdanelis 2003). Greek polar questions in particular have been analysed by Arvaniti, Ladd \& Mennen (2006), Arvaniti (2009) and Baltazani (2007). Arvaniti (2009) reports that the autosegmental representation of the polar question melody is $\mathrm{L} * \mathrm{~L}+\mathrm{H}-\mathrm{L} \%$ whereby the rise-fall pitch movement shows two possible alignments with the segmental string depending on where the focus of the question lies. If the focused word is the final word of the utterance, the L* pitch accent (the nucleus of the question) co-occurs with the stressed syllable of the final word and the $\mathrm{L}+\mathrm{H}-\mathrm{L} \%$ phrase accent and boundary tone occur on the last syllable of the utterance (see figure 1). If, on the other hand the focused item is not the final word of the utterance, the L* pitch accent appears on the stressed syllable of the focused item, the $\mathrm{L}+\mathrm{H}$ - phrase accent co-occurs with the stressed syllable of the final word and the $L \%$ boundary tone appears on the last syllable of the utterance (see figure 2 ).

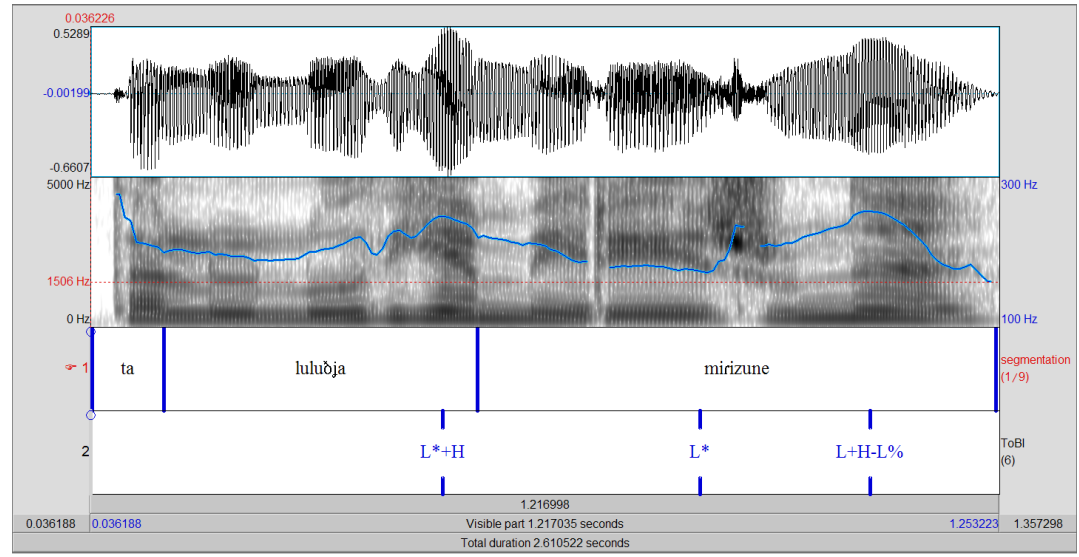

Figure 1. Spectrogram, phonetic transcription and tonal transcription of the Greek polar question /ta lu'luðja mi'rizune/ "Do flowers smell?" (example replicated from Arvaniti \& Baltazani 2005). The superimposed blue line represents the Fo contour. The L* co-occurs with the stressed syllable of the final word and the $\mathrm{L}+\mathrm{H}-\mathrm{L} \%$ phrase accent and boundary tone co-occur with the final syllable of the last word, indicating that the focused item of the utterance is the final one. 


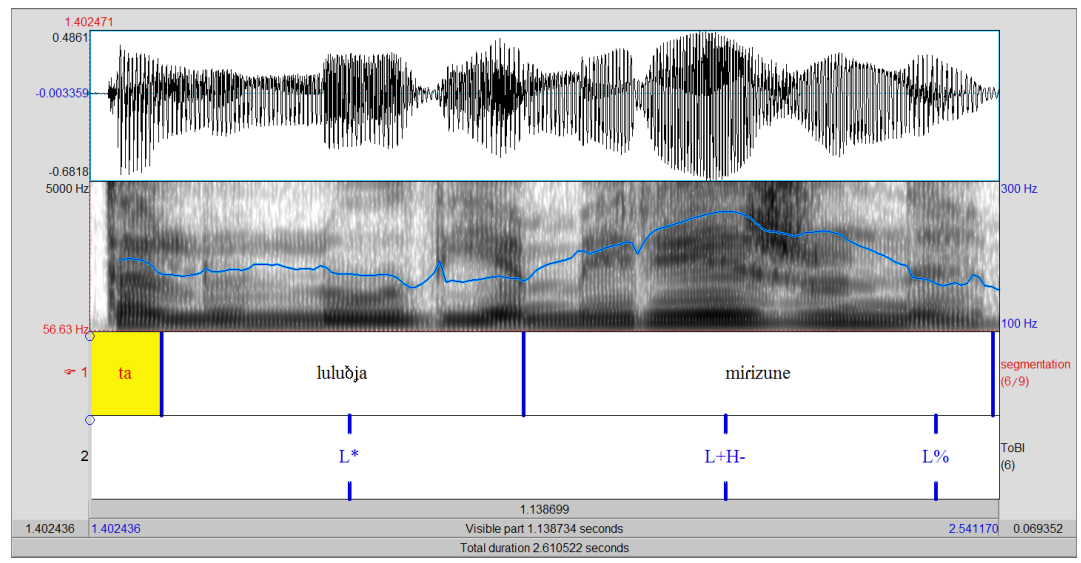

Figure 2. Spectrogram, phonetic transcription and tonal transcription of the Greek polar question /ta lu'luðja mi'rizune/ "Do flowers smell?" (example replicated from Arvaniti \& Baltazani 2005).

The superimposed blue line represents the Fo contour. The L* pitch accent aligns with the stressed syllable of the non-final word, the $\mathrm{L}+\mathrm{H}$ - phrase accent co-occurs with the stressed syllable of the final word and the L\% co-occurs with the final syllable of the final item of the utterance, indicating that the focused item of the utterance is not the final one.

While Greek polar questions involve a rise-fall pitch movement at the end of the question, English polar questions are signaled via a range of possible contours. Within the AM framework, Grabe, Post \& Nolan (2001) and Grabe (2004) have shown that the three most common ones are: (a) a final rise pitch movement that takes the form of L*H H\%; (b) a final (fall-)rise pitch movement that takes the form of $\mathrm{H}^{*} \mathrm{~L} \mathrm{H} \%$; and (c) a final fall pitch movement that takes the form of $\mathrm{H} * \mathrm{~L} \%$ (see figures $3-5$ respectively).

Greek and English therefore differ fundamentally in the use of intonation for expressing polar questions (letting aside any differences in the use of tonal targets in prenuclear position in polar questions); where Greek has a rise-fall pitch movement at the end of the question, English may have a rise, a fall-rise or a fall.

\subsection{Pitch Range}

Languages differ not only in terms of their phonological inventory of intonational targets or the phonetic manifestation of those targets but also in terms of the range of pitch they use. Pitch range can be analyzed as varying along two dimensions, namely pitch level and pitch span (Ladd 2008). Pitch level refers to the height of overall pitch (high, mid or low) and pitch span refers to the range of frequencies used (wide or narrow). For example, German has been found to 

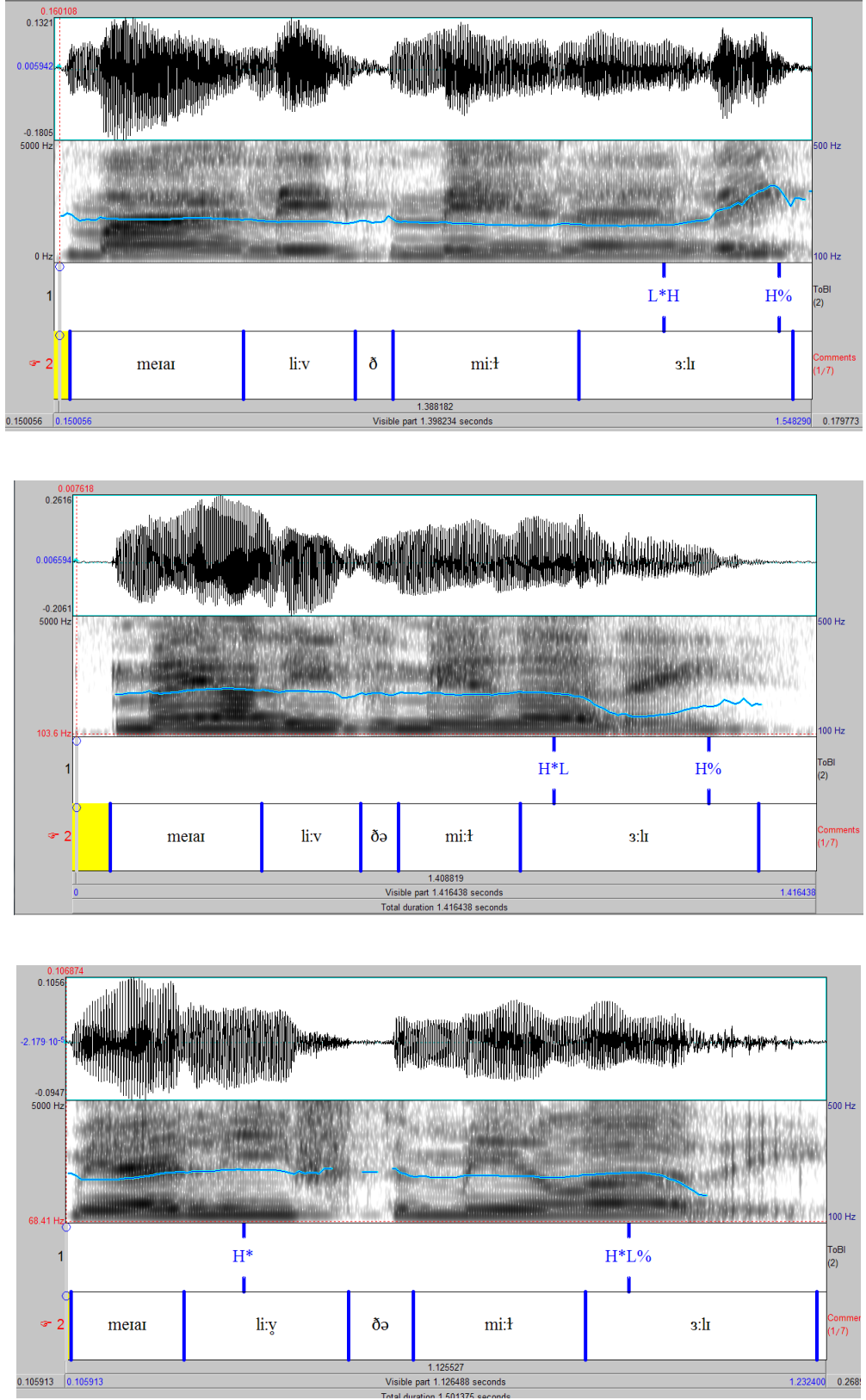

Figures 3-5. Spectrogram, tonal transcription and phonetic transcription of the English polar question "May I leave the meal early?" uttered using the three most common intonation contours in English polar questions, namely L*H H\% (final rise), $\mathrm{H} * \mathrm{~L} \mathrm{H} \%$ (final fall-rise) and $\mathrm{H} * \mathrm{~L} \%$ (final fall). The materials are taken from the freely available IViE corpus (Grabe et al. 2001). 
employ lower pitch level and narrower pitch span than English (Mennen 2007; Mennen et al. 2007). Such cross-linguistic differences may give rise to emerging stereotypes about national and linguistic groups. For example, the use of narrower pitch range may make German speakers sound 'bored' or 'unfriendly' to English speakers and, reversely, the use of a wider pitch range may make English speakers sound 'overexcited' or 'aggressive' to German speakers. Additionally to such cross-linguistic differences in the use of pitch range, there is evidence that $L 2$ learners use a narrower pitch range than native speakers of the target language (Backman 1979; Willems 1982). However, given potential crosslinguistic differences in pitch range, if an $L 2$ learner is found to use a narrower pitch range than the one used in the target language, this may simply mean that the learner is using her L1 pitch range. In order to rule out this possibility, it is therefore necessary to also obtain baseline measures of the learner's L1 pitch range.

\subsection{Research Questions}

The current study addresses the following research questions:

1. How do Greek learners of English produce English polar questions?

a) Do they transfer their L1 (Greek) intonational targets?

b) Have they acquired the L2 (English) intonational targets?

2. How do Greek learners of English use pitch range when speaking English?

a) Do the two languages differ in terms of pitch range?

b) If not, do Greek speakers use a narrower pitch range when speaking English?

\section{Method}

\subsection{Participants}

The participants were 7 Greek learners of English from Athens (4 male, 3 female), aged 12-15 years, all intermediate learners of English. None had spent a period of more than one week in an English-speaking country. They were asked to read polar questions in Greek and English. They were also asked to read the Cinderella story in both languages for the purpose of obtaining pitch range measurements. Comparable materials (i.e., English polar questions and the Cinderella story in English) spoken by native English speakers were taken from the freely available IViE Corpus (Grabe et al. 2001). Six English speakers from Cambridge ( 3 male, 3 female) were used with a mean age of around 15 years old. 


\subsection{Speech Materials and Procedure}

Participants were recorded using a MicroTrack 24/96 digital recorder at a sampling rate of $44.1 \mathrm{kHz}$. They read the sentences from script and were not given any instructions as to the placement of focus in each question. Polar questions were matched for number of syllables and position of stress across languages. There were 4 polar questions in Greek and 4 questions in English (see table 1). Fillers were also included containing statements and wh-questions. The sentences were blocked by language and were fully randomized within each language. All sentences were read three times by each Greek speaker. English sentences preceded Greek sentences to avoid any interference from Greek. The participants read a few sentences before the actual recordings to familiarize themselves with the procedure.

Table 1.

English sentences read by native English speakers (taken from the IViE corpus) and Greek and English sentences read by Greek learners of English.

\begin{tabular}{|c|c|c|}
\hline English L1 & Greek L1 & English L2 \\
\hline May I lean on the railings? & 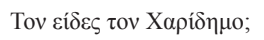 & Have you seen Haridimos? \\
\hline $\begin{array}{l}\text { May I leave the meal } \\
\text { early? }\end{array}$ & 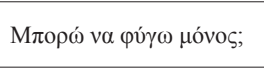 & May I leave the meal early? \\
\hline \multirow[t]{2}{*}{ Will you live in Ealing? } & $\Theta \alpha \mu$ siveı५ $\sigma \tau \eta \Lambda \eta ́ \mu v o$ & Will you live in Limnos? \\
\hline & $\mathrm{T \eta} \gamma \nu \omega \rho i \zeta \zeta \varepsilon \tau \varepsilon \tau \eta v^{\prime} \mathrm{E} \lambda \varepsilon v \alpha$ & Have you been introduced to Helena? \\
\hline
\end{tabular}

Following Grabe (2004) and in order to obtain representative measurements of pitch range in each language, after reading the sentence materials Greek speakers read the Cinderella story, first in English and then in Greek (the two passages were matched for type and length of sentences across languages).

English and Greek polar questions were transcribed in Praat (Boersma \& Weenink 2009) using the ToBI system (see Arvaniti \& Baltazani 2005 for Greek and Grabe et al. 2001 for English) and the percentage of times each pitch contour appeared on the data was measured (since this is an exploratory study we are interested in whether Greek learners have acquired the English tonal targets in polar questions leaving the examination of the exact phonetic realization of those targets for future research).

For pitch level, Fo frequency $(\mathrm{Hz})$ from the Cinderella story was calculated. For pitch span, three measurements, all in semitones (ST), were taken: (a) $80 \%$ range (i.e., the difference between the $90^{\text {th }}$ and the $10^{\text {th }}$ percentile); (b) interquartile range (IOR) (i.e., the difference between the $75^{\text {th }}$ and the $25^{\text {th }}$ percentile, in other words the middle $50 \%$ of the observations); and (c) +/- 2 standard deviations around the mean. 


\section{Results}

\subsection{Polar Questions}

Figure 6 shows percentage tune selection for signalling English polar questions by native English speakers. The two rise pitch movements (i.e., $\mathrm{H} * \mathrm{~L} \mathrm{H} \%$ and $\mathrm{L} * \mathrm{H}$ $\mathrm{H} \%$ ) were used about $57 \%$ of times (around $33 \%$ and $23 \%$ respectively) and the fall pitch movement (i.e., $H^{*} \mathrm{~L} \%$ ) was used about $43 \%$ of times. A learner of English is therefore required to use at least one of these three tunes to successfully approximate the way English speakers signal polar questions.

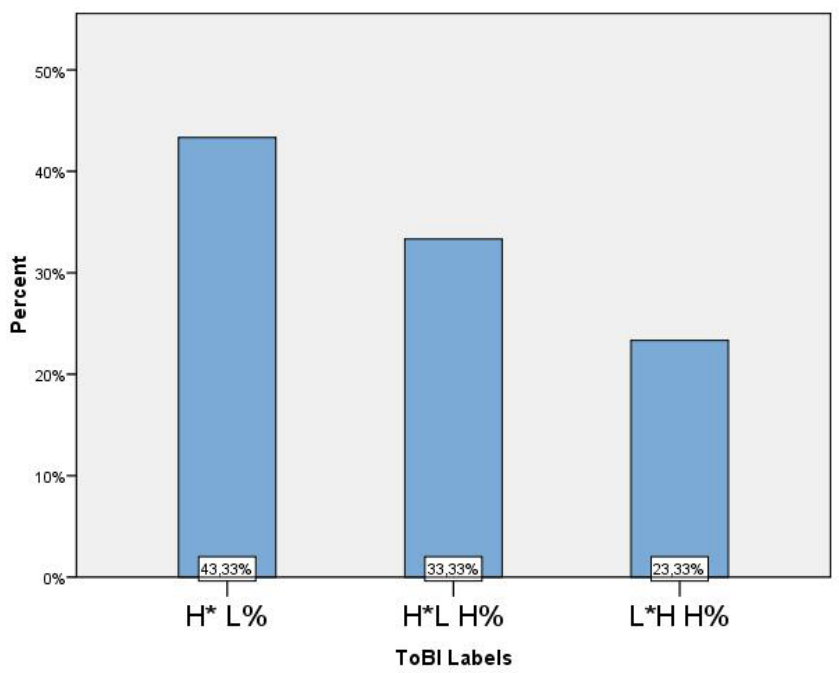

Figure 6. Percentage tune selection by English speakers in English polar questions. $H * L \%$ corresponds to a final fall pitch movement at the end of the question; $\mathrm{H} * \mathrm{~L} \mathrm{H} \%$ corresponds to a final (fall-)rise pith movement; and L*H H\% corresponds to a rise pitch movement towards the end of the question (see Grabe et al 2001).

Figure 7 shows percentage tune selection for signalling Greek polar questions (blue bars) and English polar questions (grey bars) by native Greek speakers. For representation reasons, the label $L * L+H-L \%$ refers to utterances with focus in a non-final word of the question and the label $L *+H L * L+H-L \%$ refers to questions with focus in the final word of the question. Greek speakers used the expected rise fall pitch movement to signal Greek polar questions. They predominantly (around 90\%) placed the focus of the question on the non-final word, indicating a clear preference for this realisation when no instructions are given to participants regarding focus placement. 


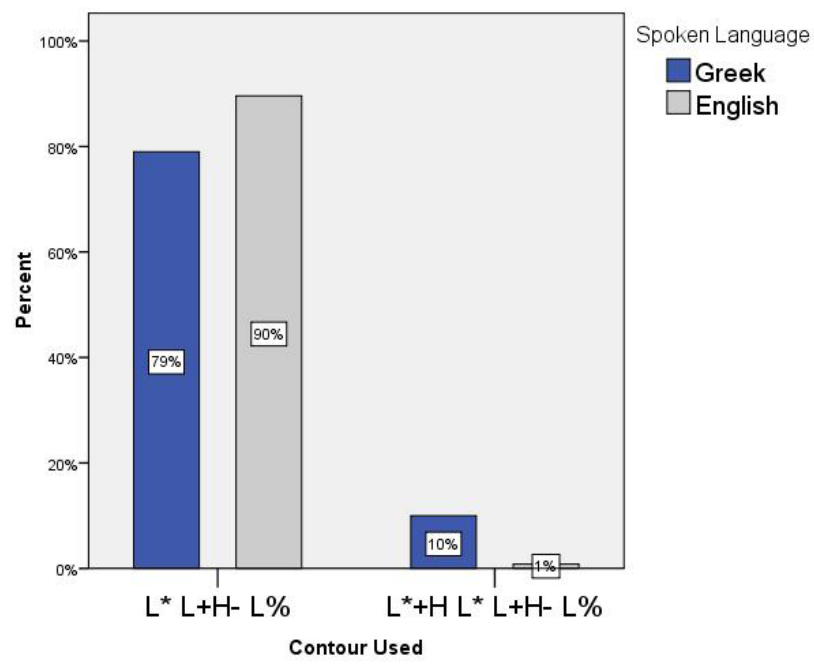

Figure 7. Percentage tune selection by Greek speakers in English polar questions (blue bars) and in Greek polar questions (grey bars). $\mathrm{L} * \mathrm{~L}+\mathrm{H}-\mathrm{L} \%$ refers in this graph to utterances with focus in a non-final word of the question and $\mathrm{L*}+\mathrm{L} \mathrm{L} * \mathrm{~L}+\mathrm{H}-\mathrm{L} \%$ refers to utterances with focus in the final word of the question.

Importantly, Greek speakers transferred their L1 intonation in polar questions (including focus placement) when producing English polar questions, i.e., they exclusively used the 'Greek' rise-fall tune in English without demonstrating any sign that they have acquired either of the tunes used by native English speakers in polar questions (see figure 8).

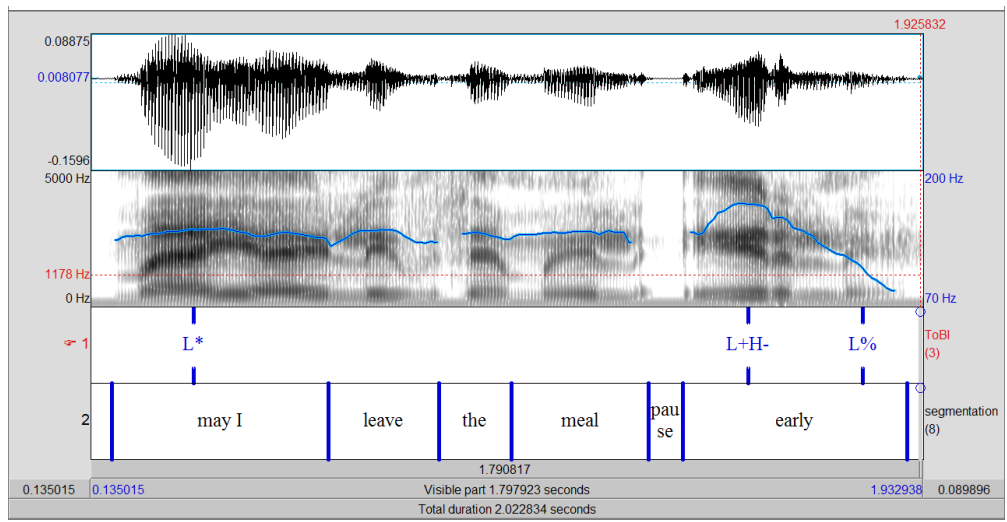

Figure 8. Spectrogram and tonal transcription of the question "May I leave the meal early?" spoken by a Greek learner of English, showing a complete transfer of the learner's L1 (Greek) polar question intonation to English polar questions. The word "may" is in focus and carries the L* pitch accent. The final stressed syllable of the question (i.e., the first syllable of "early") carries an $\mathrm{L}+\mathrm{H}$ phrase accent. The boundary tone is an $\mathrm{L} \%$ as we would expect if this were a Greek polar question. 


\subsection{Pitch Range}

Table 2 shows mean values and statistical comparisons for pitch range (three measurements of pitch span and one measurement of pitch level) obtained for Greek learners of English and for native English speakers. Greek and English did not differ in terms of pitch span across measurements (the English pitch span was somewhat wider than in Greek but this difference was not statistically significant). However, Greek speakers' pitch span in English was narrower than both the native English one and their own native in Greek, indicating that their speech was more monotonous and with less pitch variation in English than in Greek. Furthermore, Greek speakers' pitch level was significantly lower when speaking English than when speaking Greek (no statistical comparison can be made between Greek and English speakers' pitch level for pitch level being an absolute measurement).

Table 2

Mean values of pitch range (three measurements of pitch span in ST and one measurement of pitch level in Hz) for Greek speakers in L1 (Greek) and L2 (English) and for English speakers in L1 (English). The results of $t$-tests (Bonferroni-adjusted) comparing mean values are also given.

\begin{tabular}{|l|c|c|c|c|c|}
\hline & L1 Greek & L2 English & L1 English & L1 Greek vs. L2 English & L2 English vs. L1 English \\
\hline $\mathbf{8 0 \%}$ (ST) & 6.82 & 7.96 & 4.85 & $\mathrm{t}(6)=4.562, p<.001$ & $\mathrm{t}(11)=-5.107, p<.001$ \\
\hline IQR (ST) & 3.73 & 4.23 & 2.50 & $\mathrm{t}(6)=5.741, p<.001$ & $\mathrm{t}(11)=-5.122, p<.001$ \\
\hline SD4 (ST) & 9.75 & 10.20 & 8.01 & $\mathrm{t}(6)=3.128, p<.01$ & $\mathrm{t}(11)=2.838 p<.01$ \\
\hline Level (Hz) & 196 & 180 & 188 & $\mathrm{t}(6)=3.119, p<.01$ & n.c. \\
\hline
\end{tabular}

n.c. $=$ non-comparable data

\section{Discussion}

The current study is part of a larger project that examines, for the first time in the literature, the production of English intonation by Greek learners of English. The analysis of intonation follows the AM theory for intonational analysis (Pierrehumbert 1980; Ladd 2008). Here we focus on the production of English polar questions by intermediate learners of English and their range of pitch when speaking English. Baseline productions uttered by the same Greek speakers and by native English speakers were used for control reasons. The results showed that learners transferred the Greek tune (i.e., a rise-fall movement at the end of the utterance) in English polar questions. There was no evidence that they have acquired any of the patterns used by native English speakers for signalling polar questions. This $L 1$ transfer effect on the learning of $L 2$ intonation is consistent 
with previous work on L2 intonation (e.g. Jun \& Oh 2000; Mennen 2004, 2006) and with previous work on L2 segmentals (e.g. Best et al. 2001; Flege \& Mackay 2004; Iverson \& Evans 2007; Iverson et al. 2003; Lengeris 2009; Lengeris \& Hazan, 2010).

Regarding the use of pitch range in the two languages, the comparison of baseline productions by native speakers of Greek and English showed no crosslinguistic differences in the use of pitch span. However, Greek speakers' pitch span in English was narrower from both their Greek pitch span and from the target (English) pitch span, indicating an L2 production effort strategy (Backman 1979; Willems 1982). This was corroborated by the finding that Greek speakers also showed lower pitch level in English than in Greek.

The results of the current study put forward a number of directions for future research on the acquisition of English intonation by Greek speakers. After having established that intermediate learners transfer their L1 (Greek) tonal targets in English polar questions, the next step for this research entails a detailed phonetic analysis of the exact manifestation of those targets (e.g. Fo peak alignment) in English polar questions and an examination of how this compares to the alignment of tonal targets in L1 (Greek). Future plans also include an analysis of phonological targets and their phonetic manifestation in other types of sentences such as wh-questions, polar questions and statements by both intermediate and advanced Greek learners of English. For example, the learning of wh-questions by Greek speakers is another interesting L1/L2 case because Greek and English use completely different intonation patterns in signalling wh-questions; Greek uses a final rise pitch movement at the end of the question while English uses a final fall pitch movement. The ultimate goal of this research is to apply our understanding of the relationship between Greek and English intonation to improve the learning of English intonation by Greek speakers via the use of computer-based training. The training stimuli will comprise of intonation contours spoken by native English speakers and re-synthesized intonation patterns based on each trainee's Greek-accented English production.

\section{Acknowledgments}

We would like to thank the students of the Foreign Language Center "Psychidou" for their participation, as well as an anonymous reviewer for their constructive comments. 


\section{References}

Arvaniti, A. 2007. Greek Phonetics: State of the Art. Journal of Greek Linguistics 8: $97-208$.

Arvaniti, A. 2009. Greek intonation and the phonology of prosody: polar questions revisited. Proceedings of the $8^{\text {th }}$ International Conference on Greek Linguistics, 14-29.

Arvaniti, A. and Baltazani, M. 2005. Intonational analysis and prosodic annotation of Greek spoken corpora. In S.-A. Jun (ed.), Prosodic Typology: The Phonology of Intonation and Phrasing. Oxford University Press, 84-117.

Arvaniti, A., Ladd, D.R. and Mennen, I. 2006. Tonal association and tonal alignment: evidence from Greek polar questions and contrastive statements. Language and Speech 49: 421-450.

Atterer, M. and Ladd, D.R. 2004. On the phonetics and phonology of "segmental anchoring" of FO: evidence from German. Journal of Phonetics 32: 177-197.

Backman, N. 1979. Intonation errors in second language pronunciation of eight Spanish speaking adults learning English. Interlanguage Studies Bulletin 4(2): 239-266.

Baltazani, M. 2007. Intonation of polar questions and the location of nuclear stress in Greek. In C. Gussenhoven and T. Riad (eds.), Tones and Tunes, Volume II: Experimental Studies in Word and Sentence Prosody. Berlin: Mouton de Gruyter, 387-405.

Baltazani, M. and Jun, S.-A. 1999. Focus and Topic Intonation in Greek. Proceedings of the XIVth International Congress of Phonetic Sciences, San Francisco, 13051308. 
Best, C.T., McRoberts, G.W. and Goodell, E. 2001. Discrimination of non-native consonant contrasts varying in perceptual assimilation to the listener's native phonological system. Journal of the Acoustical Society of America 109: 775-794.

Cebrian, J. 2006. Experience and the use of non-native duration in L2 vowel categorization. Journal of Phonetics 34: 372-387.

Derwing, T.M., Munro, M.J. and Wiebe, G. 1998. Evidence in favour of a broad framework for pronunciation instruction. Language Learning 48: 393-410.

Flege, J.E. 1995. Second language speech learning: Theory, findings, and problems. In W. Strange (ed.), Speech perception and linguistic experience: Issues in cross-language research. Baltimore: York Press, 233-277.

Flege, J.E. and Mackay, I.R.A. 2004. Perceiving vowels in a second language. Studies in Second Language Acquisition 26: 1-34.

Flege, J.E., MacKay, I.R.A. and Meador, D. 1999. Native Italian speakers' production and perception of English vowels. Journal of the Acoustical Society of America 106: 2973-2987.

Grabe, E. 2004. Intonational variation in urban dialects of English spoken in the British Isles. In P. Gilles and J. Peters (ed.), Regional Variation in Intonation. Tuebingen: Niemeyer, 9-31.

Grabe, E., Post, B. and Nolan, F. 2001. Modelling intonational Variation in English. The IViE system. In S. Puppel and G. Demenko (ed.), Proceedings of Prosody 2000, Adam Mickiewitz University, Poznan, 51-57.

Guion, S.G., Flege, J.E., Akahane-Yamada, R. and Pruitt, J.C. 2000. An investigation of current models of second language speech perception: The case of Japanese adults' perception of English consonants. Journal of the Acoustical Society of America 107: 2711-2724.

Hahn, L.D. 2004. Primary stress and intelligibility: research to motivate the teaching of suprasegmentals. TESOL Quarterly 38: 201-223.

Hattori, K. and Iverson, P. 2009. English /r/-/l/ category assimilation by Japanese adults: Individual differences and the link to identification accuracy. Journal of the Acoustical Society of America 125: 469-479. 
Iverson, P. and Evans, B.G. 2007. Learning English vowels with different first language vowel systems: Perception of formant targets, formant movement, and duration. Journal of the Acoustical Society of America 122: 2842-2854.

Iverson, P., Kuhl, P.K., Akahane-Yamada, R., Diesch, E., Tohkura, Y. and Kettermann, A. 2003. A perceptual interference account of acquisition difficulties for nonnative phonemes. Cognition 87: 47-57.

Jilka, M. 2000. The contribution of intonation to the perception of foreign accent. PhD dissertation, University of Stuttgart.

Jun, S.-A. and Oh, M. 2000. Acquisition of $2^{\text {nd }}$ language intonation. Proceedings of International Conference on Spoken Language Processing, 76-79.

Kainada, E. 2010. The phonetic and phonological nature of prosodic boundaries: evidence from Modern Greek. PhD Thesis, University of Edinburgh.

Kang, O. 2010. Relative salience of suprasegmental features on judgments of $L 2$ comprehensibility and accentedness. System 38: 301-315.

Kang, O., Rubin, D. and Pickering, L. 2010. Suprasegmental measures of accentedness and judgments of English language learner proficiency in oral English. Modern Language Journal 94: 554-566.

Ladd, D.R. 2008. Intonational Phonology. Cambridge University Press, $2^{\text {nd }}$ Edition.

Lengeris, A. 2009. Perceptual assimilation and L2 learning: Evidence from the perception of Southern British English vowels by native speakers of Greek and Japanese. Phonetica 66: 169-187.

Lengeris, A. and Hazan, V. 2010. The effect of native vowel processing ability and frequency discrimination acuity on the phonetic training of English vowels for native speakers of Greek. Journal of the Acoustical Society of America 128: 3757-3768.

Mackay, I.R.A., Meador, D. and Flege, J.E. 2001. The identification of English consonants by native speakers of Italian. Phonetica 58: 103-125.

Mennen, I. 2004. Bi-directional interference in the intonation of Dutch speakers of Greek. Journal of Phonetics 32: 543-563. 
Mennen, I. 2006. Phonetic and phonological influences in non-native intonation: an overview for language teachers. OMUC Speech Science Research Centre Working Papers WP-9.

Mennen, I. 2007. Phonological and phonetic influences in non-native intonation. In Trouvain, J. and Gut, U. (ed.), Non-native Prosody: Phonetic Descriptions and Teaching 2 Practice (Nicht-muttersprachliche Prosodie: phonetische Beschreibungen und didaktische Praxis). Mouton De Gruyter.

Mennen, I., Schaeffler, F. and Docherty, G. 2007. Pitching it differently: a comparison of the pitch ranges of German and English speakers. Proceedings of the 16th International Congress of Phonetic Sciences. University of Saarbruecken.

Munro, M. 1995. Nonsegmental factors in foreign accent. Studies in Second Language Acquisition 17: 17-34.

Munro, M. and Derwing, T. 1999. Foreign accent, comprehensibility, and intelligibility in the speech of second language learners. Language Learning 49 Supplement 1: 285-310.

Munro, M.J. and Derwing, T.M. 2001. Modelling perceptions of the comprehensibility and accentedness of L2 speech: The role of speaking rate. Studies in Second Language Acquisition 23: 451-468.

Pickering, L. 2001. The role of tone choice in improving ITA communication in the classroom. TESOL Quarterly 35: 233-255.

Pierrehumbert, J. 1980. The Phonology and Phonetics of English Intonation. PhD dissertation, MIT.

Polka, L. 1995. Linguistic influences in adult perception of non-native vowel contrasts. Journal of the Acoustical Society of America 97: 1286-1296.

Tserdanelis, G. 2003. Phonetic variation in syntactically ambiguous sentences. Studies in Greek Linguistics 23: 931-942.

Willems, N.J. 1982. English intonation from a Dutch point of view. Dordrecht: Foris Publications. 
Major Trends in Theoretical and Applied Linguistics 